\title{
MODELING OF THE CONTROLLED AIR SPRING
}

\author{
RÁGULÍK Jiří1, SIVČÁK Michal ${ }^{1}$
}

${ }^{1}$ TUL - Technical University of Liberec, Faculty of Mechanical Engineering, Department of Applied Mechanics, Studentská 1402/2, 46117 Liberec I, Czech Republic, e-mail: jiri.ragulik@tul.cz.

\begin{abstract}
The pneumatic springs are frequently used as a machine component. They are mainly used for passive vibration damping with the possibility to regulate the working height of the springs. The paper describes the creation of a mathematical model of a spring controlled thru the PID regulator. At conclusion are summarized the limits of PID control and sketches the future possibility of substituting the PID controller by a neural network.
\end{abstract}

KEYWORDS: Air springs, PID regulation, mathematical model

\section{Introduction}

Pneumatic springs are most commonly used to suspend vehicle axles, as well as elements to eliminate machine vibration. These springs use compressed gas inside the bellows as a springing medium. Their main advantage over cheaper and simpler conventional springs is the ability to change their characteristics by changing the internal pressure [1]. Appropriate regulation of the internal overpressure can thus achieve the desired system properties, which can be changed as needed even during the operation [2].

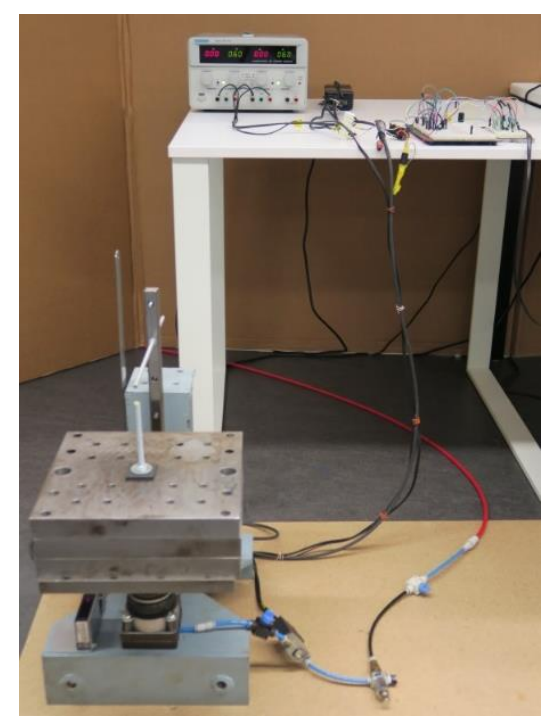

Fig. 1 Assembled control system

The control system formed (Fig. 1) consists of the spring itself, the frame, the weight, the compressed air source, the SMC VY1A00 pressure valve, the optoNCDT 1402-200 laser position sensor, and an electronic circuit that includes the controller. The lower spring lid, through which overpressure is supplied to the spring, is clamped to the frame. The upper spring cover is fastened to the movable part of the frame by a screw connection, the plate on which the weight is placed. This position is read by the laser position sensor. The output of the laser sensor is the voltage that is applied to the electronic circuit, in which the difference of measured 
and desired voltage is applied to the PID controller. The sum of the outputs of each controller component is inverted and applied to the pressure regulator terminals.

\section{Mathematical model of spring}

In order to verify the functionality of the whole system and especially the assembled electronic circuit in the software MapleSim, it was necessary to create a mathematical model of the pneumatic spring, i.e. its force characteristic.

Several simplifications have been considered in deriving this characteristic. The most important thing was considering the gas in the spring as an ideal gas. If no liquefaction or humidification of air is expected, this model is accurate enough. Another simplification is the consideration of spring deformation as reversible changes.

$$
\begin{gathered}
F(x)=\left(A_{0}+A_{1} \cdot x+A_{2} \cdot x^{2}\right) \cdot p_{p}+k_{1} \cdot x+k_{2} \cdot x^{2}+k_{3} \cdot x^{3} \\
F\left(x, p_{0}\right)=\left(\frac{p_{0} \cdot V_{0}}{V_{0}-A_{0} \cdot x-\frac{1}{2} A_{1} \cdot x^{2}-\frac{1}{3} A_{2} \cdot x^{3}}\right) \cdot\left(A_{0}+A_{1} \cdot x+A_{2} \cdot x^{2}\right) \\
+k_{1} \cdot x+k_{2} \cdot x^{2}+k_{3} \cdot x^{3}
\end{gathered}
$$

Measurements of the examined air spring DUNLOP $23 / 4$ x 3, necessary to obtain unknown constants, were made on a loading device TIRA test (Fig. 2). For the purpose of this measurement, a pneumatic circuit was constructed to allow air inlet and outlet and pressure and temperature measurements. Measured data was fitted to the mathematical model by least squares method (Fig. 3), which is a standard approach in regression analysis to approximate the solution of overdetermined systems of equations.

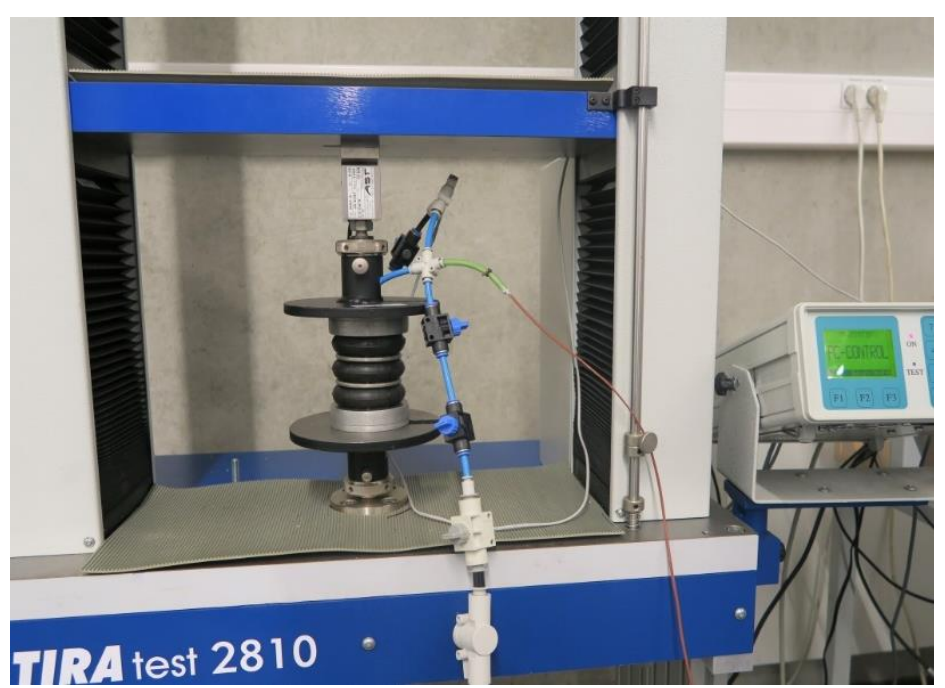

Fig. 2 Air spring with attached pneumatic circuit clamped in load machine

First, the measurement was carried out without air intake, thereby obtaining data to determine the bellows stiffness coefficients $k_{1}, k_{2}$ and $k_{3}$. Subsequently, the measurement was already carried out with the supply of compressed air. The obtained data together with the already known stiffness coefficients are used to obtain the coefficients of the effective spring surface $A_{0}, A_{1}$ and $A_{2}$ (Table 1). In equations (1) and (2), $p_{0}$ stands for initial overpressure, $p_{p}$ for overpressure and $V_{0}$ for initial volume of the air spring. The volume of the investigated 
spring at a free length is $160 \mathrm{ml}$, which is the value given by the manufacturer. The accuracy of this parameter has been verified by measuring with a measuring cylinder.

Table 1 Calculated coefficients

\begin{tabular}{|c|r|c|}
\hline Coefficient & \multicolumn{1}{|c|}{ Value } & Unit \\
\hline$k_{1}$ & 5202.87 & $\mathrm{~N} \cdot \mathrm{m}^{-1}$ \\
\hline$k_{2}$ & 74825 & $\mathrm{~N} \cdot \mathrm{m}^{-2}$ \\
\hline$k_{3}$ & 5403911 & $\mathrm{~N} \cdot \mathrm{m}^{-3}$ \\
\hline$A_{0}$ & 0.0022638 & $\mathrm{~m}^{2}$ \\
\hline$A_{1}$ & 0.04305 & $\mathrm{~m}$ \\
\hline$A_{2}$ & -0.06123 & 1 \\
\hline
\end{tabular}

The accuracy of the acquired model is sufficient to verify system functionality and simulate its behaviour. The absolute value of the approximated and measured force difference reaches a maximum of $89 \mathrm{~N}$ when measured with the highest free length pressure, namely $1622 \mathrm{~N}$. The difference value is $5.5 \%$ of the measured value. The maximum percentage difference occurs at minimum pressure at free length, which is outside the assumed working area of the spring under investigation. In the entire working area of the given spring, the error is up to $10 \%$, which can be considered as very satisfying.

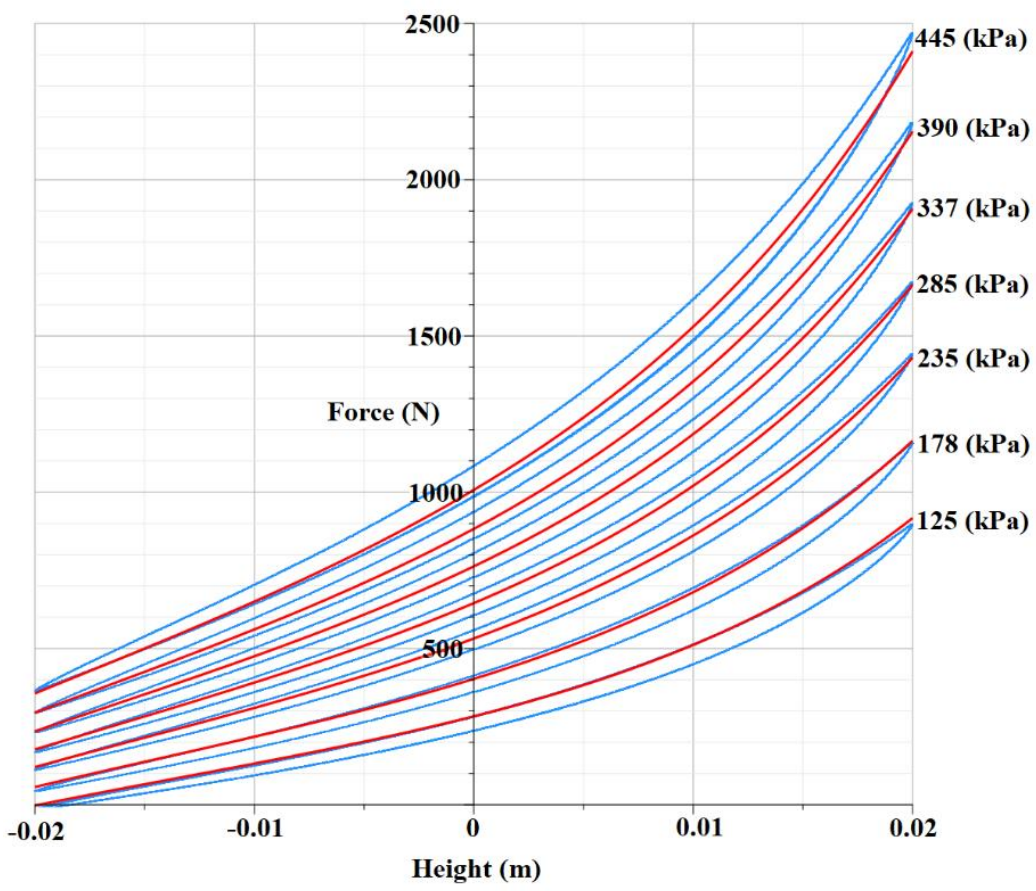

Fig. 3 Approximated (red) and measured (blue) force dependence on spring height for individual pressures for closed system

The events that cause inaccuracy take place mainly in the material of the pneumatic spring - rubber bellows [3] [4]. These phenomena were not taken into account in the mathematical model to maintain its simplicity. 


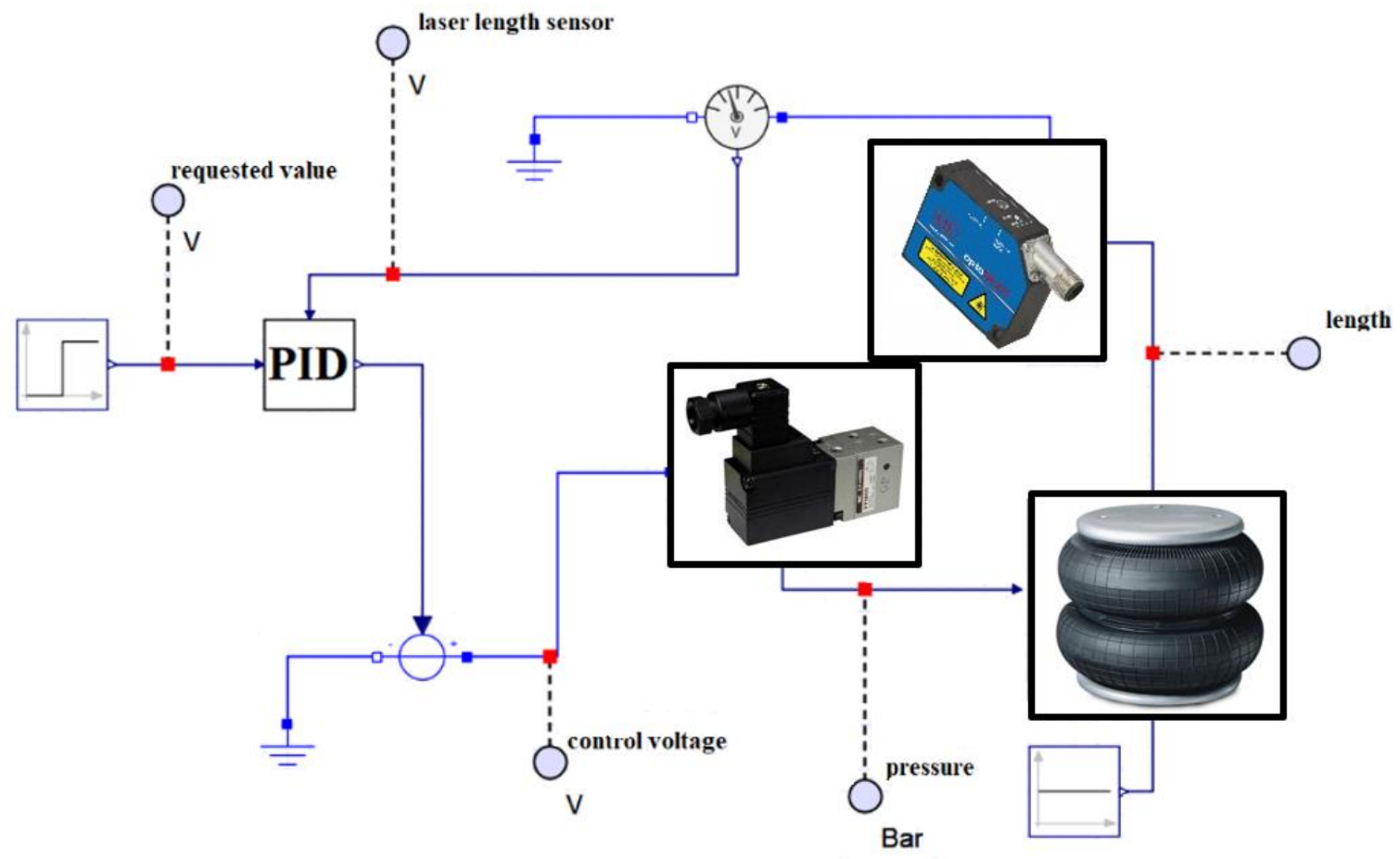

Fig. 4 Model created in MapleSim used to verify system functionality

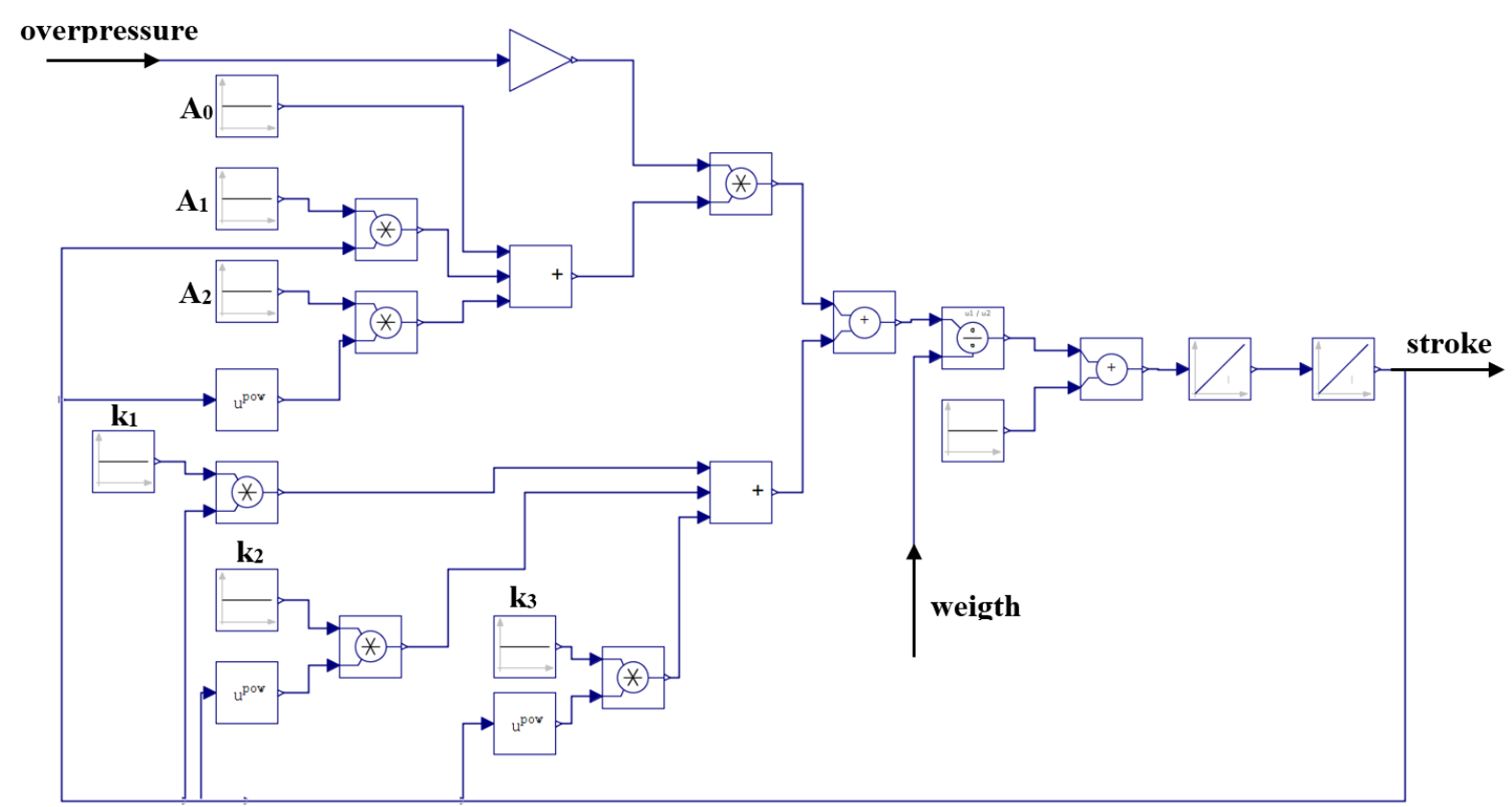

Fig. 5 Mathematical model of air spring created in MapleSim

The acquired mathematical model was created in MapleSim software and its functionality was confirmed (Fig. 4). (Fig. 5) shows a detail of an air spring submodel.

\section{Spring height control}

There are a number of approaches to setting up a PID controller. From the simplest method of trial-and-error, through the manual setup of the Wade method, to the time-tested and longused methods, such as the Ziegler-Nichols method, which has been used. The method consists in bringing the system with the integration and derivative components turned off to the stability 
limit, where output of the control loop has stable and consistent oscillations. It is a state of the system where constant amplitude of oscillations is obtained after excitation. The proportional gain is set to a minimum and a step load is performed. Proportional gain is increased until the system is just on the stability level. The gain of $k^{*}$ at which this state has been reached is one of the two parameters needed to determine the appropriate controller setting. The second parameter is the period of critical oscillations $T^{*}[5]$.

The system was excited by a free fall of a $7 \mathrm{~kg}$ steel weight from a constant height of approximately $25 \mathrm{~cm}$. This excitation was chosen for its simplicity and good repeatability. The value of the critical gain $k^{*}=1.5$ and the period of critical oscillations $T^{*}=0.24 \mathrm{~s}$ were determined. The values of the gain of the individual components of the regulator were calculated from these values. In this way a virtual PID controller created in LabVIEW environment has been set up.

The electronic circuitry including the PID controller was assembled on a solderless field from operational amplifiers, resistors, capacitors, cables, and several other electronic components.

The control circuit thus formed was able to maintain a constant required height under static load throughout the working height of the spring (Fig. 6).

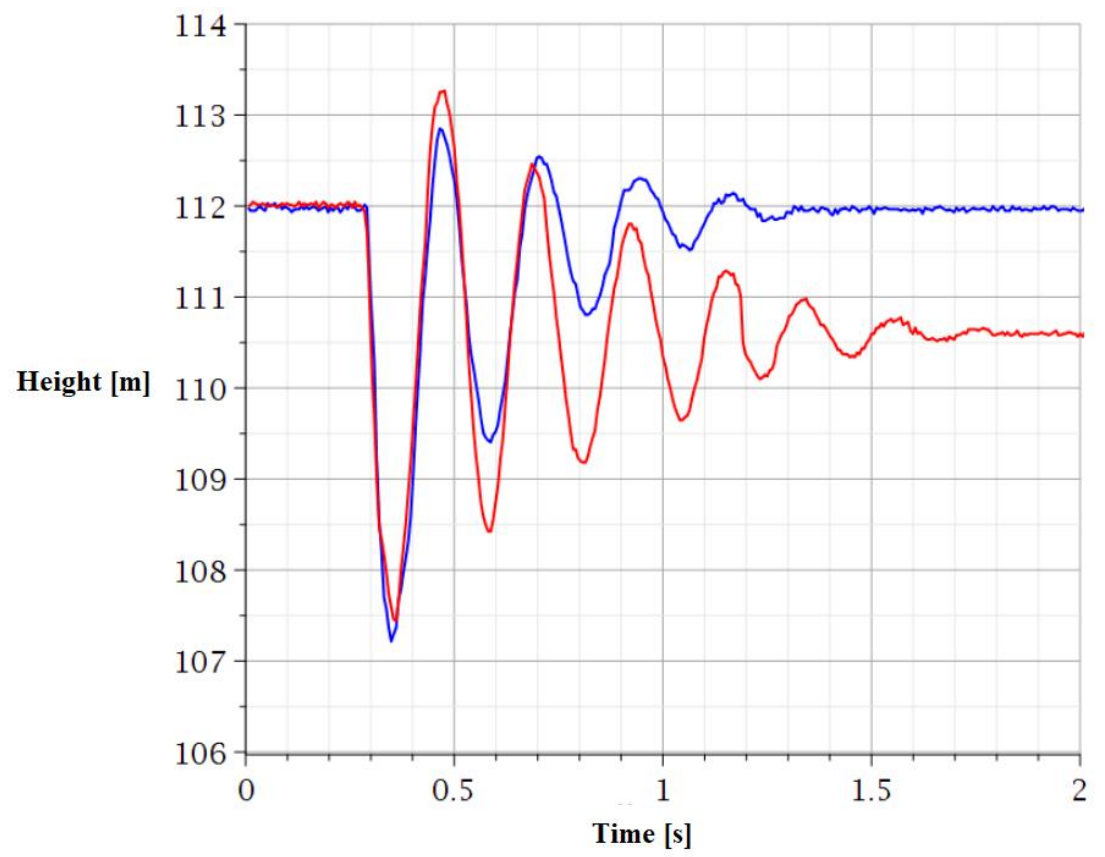

Fig. 6 Time dependence of measured change of height with on (blue) and off (red) control

\section{CONCLUSION}

A mathematical model of an air spring was created and the accuracy of the model was evaluated. The data needed to determine the unknown coefficients was obtained by measurement on a loading machine. When creating the mathematical model of the spring, a methodology was also developed for describing any bellows pneumatic spring operating as an open (1) or closed (2) system.

The control loop was then assembled and amplifications of the individual components of the PID controller were determined by well-repeatable excitations. The system is able to maintain a constant height under static loading, but under dynamic loading, the height control speed is insufficient. The solution could be to replace the analog PID controller with a microcontroller, which predictively regulates spring height using neural networks. The control of pneumatic 
springs has been dealt with by the Nagai, Moran and Tamura in the article [6], which describe the regulation of train suspension.

When a significant acceleration of altitude control and possible improvement of other parameters, such as the amount of air required and energy consumed, is found, practical applications could be considered wherever active vibroisolation is required. Such cases are, for example, the driver's seat and the means by which the vibration deteriorates working conditions and can also cause motion sickness. The great advantage of the assembled electronic circuit is the very low purchase price of the individual components, compared to prices of PID controllers available in stores.

\section{ACKNOWLEDGEMENTS}

This publication was written at the Technical University of Liberec as part of the project "Research, development and application of advanced methods and technologies in technical mechanics, biomechanics and strength and elasticity" with the support of the Specific University Research Grant, as provided by the Ministry of Education, Youth and Sports of the Czech Republic in the year 2019.

\section{REFERENCES}

[1] Sivčák, M., Škoda, J. "Verification of Active Controlled Air Spring Model”, Journal of Vibroengineering 13 (4), pp. 788 - 791, 2011.

[2] Šklíba, J., Škoda, J. "About the latest possibility of stiffness reduction of ambulance couch", Journal of Vibroengineering 11 (3), 2009.

[3] Zigo, M. "Determination of extreme properties of springs created from two mutually symmetrically sloped rubber prisms”, Strojnícky časopis - Journal of Mechanical Engineering 48 (2), pp. 97 - 105, 1997.

[4] Bouazara, M. "Optimization of the suspension parameters and tire forces analysis on a vehicle model using an analytical approach”, Strojnícky časopis - Journal of Mechanical Engineering 56 (5), pp. 257 - 272, 2005.

[5] Votrubec, R. "Control System of One-Axis Vibration-Insulation Platform with Gyroscopic-Stabilizer", Mechatronics 2013: Recent Technological and Scientific Advances. 1. vyd. Berlin: Springer International Publishing Switzerland, pp. 733 - 739, 2014. ISBN 9783319022932.

[6] Nagai, M., Moran, A., Tamura, Y., Koizumi, S. "Identification and control of nonlinear active pneumatic suspension for railway vehicles, using neural networks", Control Eng. Practice 5 (8), pp. 1137 - 1144, 1997. DOI: https://doi.org/10.1016/S09670661(97)00107-X 